\title{
Determination of Manganese in Tri Calcium Phosphate (TCP) by Atomic Absorption Spectrometry
}

\author{
Y. Yildiz ${ }^{1}$, R. Karadag², M. Cordera1, B. Gensinger ${ }^{1}$ \\ ${ }^{1}$ Centenary University Science Department, Hackettstown, NJ, USA \\ ${ }^{2}$ Istanbul Aydin University Flory Campus, Istanbul, Turkey \\ Email: *sayatoglu@yahoo.com
}

How to cite this paper: Yildiz, Y., Karadag, R., Cordera, M. and Gensinger, B. (2020) Determination of Manganese in Tri Calcium Phosphate (TCP) by Atomic Absorption Spectrometry. American Journal of Analytical Chemistry, 11, 301-308. https://doi.org/10.4236/ajac.2020.118024

Received: July 17, 2020

Accepted: August 23, 2020

Published: August 26, 2020

Copyright $\odot 2020$ by author(s) and Scientific Research Publishing Inc. This work is licensed under the Creative Commons Attribution International License (CC BY 4.0).

http://creativecommons.org/licenses/by/4.0/

\begin{abstract}
Tricalcium phosphate Anhydrous Powder typically contains less than $10 \mathrm{ppm}$ $(\mathrm{mg} / \mathrm{Kg})(\mathrm{w} / \mathrm{w})$ manganese. This level can be determined utilizing Flame Atomic Absorption Spectrometer (AAS) and standard based on known standards. A number of analytical methods are presently used for the analysis of metals in the biochemical. The instrumental techniques available are Inductively Coupled Plasma (ICP/MS), X-Ray Fluorescence, UV-VIS Spectrophotometry, and Atomic Absorption Spectrometry. Flame AA has gained widespread acceptance as an analytical technique and is used for many applications. In this study, we have determined the amount of manganese metal present in Tricalcium Phosphate (TCP) using Flame Atomic Absorption Spectrophotometer. The method has high precision and accuracy. The percent recovery was found to be $99.8 \%$ for spiked sample. The results meet the requirement.
\end{abstract}

\section{Keywords}

Manganese Determination, Tri Calcium Phosphate,

Flame Atomic Absorption Spectrometry

\section{Introduction}

Manganese $(\mathrm{Mn})$ is associated with iron in many minerals. It is a common ingredient of alloy as well as iron and steel. It is present in small amounts in many biological samples [1]. Eating a small amount of manganese each day is important in maintaining your health. Too much manganese, however, can cause se- 
rious illness. Studies in animals have shown that very high levels of manganese in food or water can cause changes in the brain [2].

Tri-calcium phosphate (TCP) is a calcium salt of phosphoric acid with the chemical formula $\mathrm{Ca}_{3}\left(\mathrm{PO}_{4}\right)_{2}$. It is known as tri-basic calcium phosphate, calcium orthophosphate, tert-calcium phosphate and bone phosphate of lime. Tri-calcium phosphate salt occurs naturally in several forms, including as a rock, in milk, in skeletons and teeth of animals and found in many nutritional supplements. Calcium phosphate rocks have a content of $30 \%$ to $40 \% \mathrm{P}_{2} \mathrm{O}_{5}$ in weight. The human body needs phosphorus as well as calcium, and tri-calcium phosphate supplies both [2]. However, tricalcium phosphate is a concentrated source of calcium and taking too much can cause high calcium levels of hypercalcemia. High levels of calcium can cause; constipation, nausea, vomiting, stomach pain, muscle pain, weakness, excessive urination. It may also cause loss of appetite, thirst, dehydration, fatigue, and mental confusion. Tricalcium is commonly used in dental powders, household items, including baby powder, toothpaste, and medically as an antacid or calcium supplement.

\section{Materials and Method}

\subsection{Reagents}

- Certified $1000 \mathrm{mg} / \mathrm{L}$ in 5\% HCl, Atomic Absorption Standard Manganese Solution, Alfa Aesar.

- Stock Standard Solution for Quality Control (QC): Manganese, $1000 \mathrm{mg} / \mathrm{L}$. Dissolve $1.000 \mathrm{~g}$ of manganese metal in a minimum volume of $(1+1) \mathrm{HNO}_{3}$. Dilute to 1 liter with $1 \%(\mathrm{v} / \mathrm{v}) \mathrm{HCl}$.

- Deionized doubly distilled water.

- Analytical grade concentrated hydrochloric acid ( $\mathrm{HCl})$, and tri-calcium phosphate (TCP) were used.

- Tricalcium Phosphate (TCP) was obtained from Morre-Tec Industries, Analytical Grade.

\subsection{Equipment/Instruments}

- Perkin Elmer 5100 PC Atomic Absorption Spectrometer with Manganese lamp and 2 inches Nitrous Oxide/Acetylene burner head.

- Lamps: Mn element hallow cathode lamp.

- Glassware: All glassware is washed in the following sequence: Alconox detergent solution, tap water, 1:1 nitric acid, tap water, 1:1 hydrochloric acid, tap water, and final rince with deionized water.

- Pipettes: 5, 10, 20, 50, 100, 200, 500, and 1000 microliters $(\mu \mathrm{L})$ pipets with disposable tips are used.

\section{Instrument/Operating Parameters}

Blank: $100 \mathrm{~mL}$ of D.I. water is taken through the digestion process.

Duplicate: A separate aliquot of random sample is digested or analysis (approximately (10\%). 
Spike: Using the formula $\mathrm{C}_{1} \mathrm{~V}_{1}=\mathrm{C}_{2} \mathrm{~V}_{2}$ an appropriate volume and concentration of standards is brought through spiked into a sample and the digestion procedure.

Instruments: Perkin-Elmer 5100 PC Atomic Absorption Spectrophotometer

Start program: Perkin-Elmer 5100 PC Atomic Absorption Spectrum

Wavelength: $403.1 \mathrm{~nm}-\mathrm{UV}$

Slit width: $0.2 \mathrm{~nm}$

Relative sensitivity: $1.0 \mu \mathrm{g} / \mathrm{mL}$

Lamp energy: 67.0

Lamp current: $20 \mathrm{~mA}$

Light source: Hallow Cathode Lamp

Burner Head: Nitrous oxide/Acetylene

Type of Flame: Nitrous oxide/Acetylene flame

Integration Time: 1.5 seconds (for optimizing only)

Average Readings: 3

\subsection{Solutons}

1) Standard Preparation: $1000 \mathrm{mg} / \mathrm{L}$ manganese stock solution.

The first consideration is preparing a set of standard is to stay within the linear range of the instrument, if a linear calibration is to be used. Refer to table, column labeled "Linear Range". That is the highest standard to be used for s linear range. Do not make standard lower than the column sensitivity. Prepare three to five standards covering the range. Pipet $25 \mathrm{~mL}$ of $1000 \mathrm{ppm}(\mathrm{mg} / \mathrm{L})$ Certified Manganese Standard Solution into a $250 \mathrm{~mL}$ volumetric flask. Add $10 \mathrm{~mL}$ of concentrated $\mathrm{HCl}$. Dilute to volume with deionized water and mix well [3]. Another consideration is preparing standards is added components.

Prepare AA standards for Manganese of 0, 0.2, 0.5, 1.0, 2.0, $5.0 \mathrm{mg} / \mathrm{L}$ with the matrix solution $1 \mathrm{~mL} 6 \mathrm{~N} \mathrm{HCl}$ per $100 \mathrm{~mL}$ solution.

2) Stock and Serial Manganese Standards for Quality Control (QC): Manganese, $1000 \mathrm{mg} / \mathrm{L}$. Dissolve $1.000 \mathrm{~g}$ of manganese metal in a minimum volume of $(1+1) \mathrm{HNO}_{3}$. Dilute to 1 liter with $1 \%(\mathrm{v} / \mathrm{v}) \mathrm{HCl}$

3) Calcium Matrix Solution, $6000 \mathrm{mg} / \mathrm{Kg}$ For the Mn test, $1.0 \mathrm{~g}$ sample is used in $100 \mathrm{~mL}$, and standard is prepared with nearly $6000 \mathrm{mg} / \mathrm{L} \mathrm{Ca}$. The sample concentration here is higher by a factor of about ten times. Accurately weigh 15 g of Calcium Carbonate and transfer to a $1000 \mathrm{~mL}$ volumetric flask. Add approximately $100 \mathrm{~mL}$ deionized water and swirl to form slurry. Add concentrated. $\mathrm{HCl}$ dropwise to affect dissolution. Allow the $\mathrm{CO}_{2}$ escape before subsequent additions of $\mathrm{HCl}$ to prevent the solution from bubbling out of the flask. When the calcium carbonate completely dissolves and the solution clears, dilute to volume with deionized water and mix well [4].

4) Sample Preparation/Acid Digestion:

Analytically weigh $1.0 \mathrm{~g}$ grams of tri-calcium phosphate and transfer to a 100 $\mathrm{mL}$ volumetric flask. Add approximately $25 \mathrm{~mL}$ of DI water and swirl to form a slurry. Then add $10 \mathrm{~mL}$ of concentrated $\mathrm{HCl}$ and swirl to dissolve. Adding acid 
to dry product can cause coagulation of the product and impede dissolution. Dilute to volume with DI water and mix well. The sample prep for determination of Mn by AA is based on the USP monograph for tricalcium phosphate, sample prep for heavy metals test [5].

\section{Procedure}

1) In a $50 \mathrm{~mL}$ beaker with glass bead weigh $2.5 \mathrm{~g}$ sample to the nearest $0.1 \mathrm{mg}$. add $18 \mathrm{~mL} 3 \mathrm{~N} \mathrm{HCl}$ and heat to boiling. Cool to room temperature, quantitatively transfer to $25 \mathrm{~mL}$ volumetric flask, and dilute to mark with water.

2) Prepare AA standards for Manganese of $0,0.2,0.5,1.0,2.0,5.0 \mathrm{mg} / \mathrm{L}$ with the matrix solution $10.72 \mathrm{~g}$ calcium chloride and $1 \mathrm{~mL} 6 \mathrm{~N} \mathrm{HCl}$ per $100 \mathrm{~mL}$ solution.

3) Run AA for Manganese as follows. Blank the instrument with water. Run water then a standard. Run water then a sample. Continue until all standards and samples have been measured.

4) Subtract average water signal from each standard reading. Construct a calibration curve and report slope, intercept, and correlation coefficient.

5) Subtract average water signal from each sample reading. Calculate concentration using calibration slope and intercept.

6) Calculate $\mathrm{mg} / \mathrm{kg}$ using the concentration in the mass taken, and the volume of solution.

\section{Experimental}

\subsection{Contamination Control}

All reagent were of a high purity grade. Eppendorf pipettes with plastic tips were used for all pipetting. All sample handling operations were conduct under a laminar flow hood to reduce atmospheric contamination.

\subsection{Calibration Standards}

The aqueous calibration standards were prepared in pre-cleaned $100-\mathrm{mL}$ volumetric flasks using glass pipettes and fixed-volume Effendorf pipette for volume transfers (Table 1 and Table 2). These standards represent the stock calibration standards were prepared.

Table 1. Serial of Mn standards from $1000 \mathrm{mg} / \mathrm{L} \mathrm{Mn} \mathrm{stock} \mathrm{solution.}$

\begin{tabular}{ccc}
\hline Working Std. Sol $(\mathrm{mL})$ & Dilute to $(\mathrm{mL})$ & Concentration of $\mathbf{M n}$ Standards $\mathbf{m g} / \mathbf{L}$ \\
\hline 0.00 & 100 & 0.00 \\
0.02 & 100 & 0.02 \\
0.05 & 100 & 0.50 \\
0,10 & 100 & 1.00 \\
0.50 & 100 & 5.00 \\
\hline
\end{tabular}


Table 2. Absorbance of Mn standards.

\begin{tabular}{cccc}
\hline Standard Concentration (mg/L) & DF & Absorbance & Blank-corrected Absorbance \\
\hline Air & 1 & 0.0000 & \\
Water & 1 & 0.0002 & \\
Blank & 1 & 0.0006 & 0.0092 \\
0.20 & 1 & 0.0263 & 0.0244 \\
0.50 & 1 & 0.0505 & 0.0481 \\
1.00 & 1 & 0.2314 & 0.2274 \\
\hline
\end{tabular}

\subsection{Background}

The technique of atomic absorption spectrometry (AAS) depends on generating a cloud of free atoms in the ground or unexcited state. The first AA spectrometers used a flame to generate atoms of the element to be determined [5]. The most common method of background correction in atomic absorption (AA) spectrophotometry uses a continuum source such as a deuterium lamp to measure the background. Background is electronically subtracted from total absorbance to give background corrected atomic absorbance [6].

\subsection{Calibration and Operation}

Before operation the calibration of the instrument is necessary. Rinse aspirator tube with D.I. water. Aspirate sample, ensure within range (between blank and highest standard). Dilute sample if necessary, and repeat for each sample.

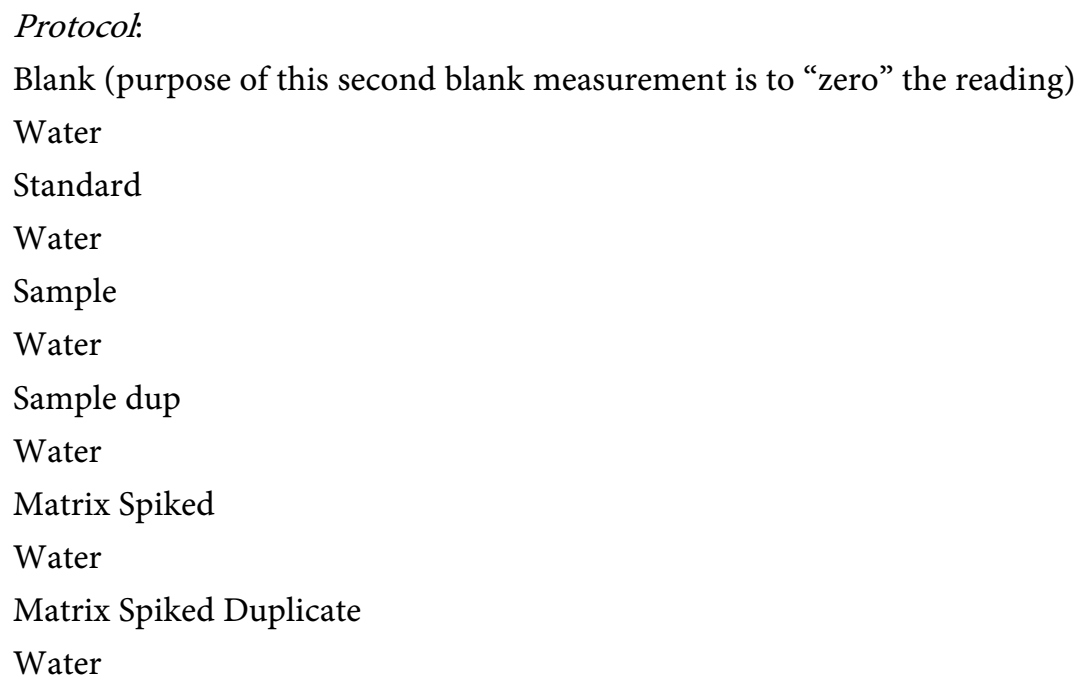

\section{Result and Discussion}

Historically, we have matched the standard matrix to the sample's matrix. When 
determining $\mathrm{Mn}$ in tricalcium phosphate, our $\mathrm{Mn}$ standards have calcium at concentrations calculated to equal those in the prepared sample solution. This may require some investigation for this reason: 1) if the reagent used for modifying the standard matrix contains, as a contaminant, traces of the element to be determined, this will artificially lower the result for the sample. 2) Therefore, use reagent of utmost purity for matrix matching standards to samples. Spike and recovery can be used to confirm that $\mathrm{Mn}$ can be determined accurately despite the fact that tricalcium phosphate sample contain $\mathrm{PO}_{4}^{3-}$.

Table 2 Raw data, absorbance of Manganese standard solutions, and the blank-corrected absorbance calculated using Equation (1).

Table 3 Data used to plot the calibration curve graph, $[\mathrm{Mn}]$ concentration and blank-corrected absorbance; slope, intercept, and $\mathrm{R}^{2}$ values for the line of best fit.

Table 4 Data of absorbance of sample solutions and spiked sample solutions, each analyzed in duplicate; concentration of Mn calculated using Equation (2) and (3).

Equation (1): Blank-corrected absorbance $=$ Observed absorbance - Blank absorbance

Equation (2): $[\mathrm{Mn}](\mathrm{mg} / \mathrm{L})=($ Blank-corrected Absorbance -0.0059$) / 0.0005$

Equation (3): $[\mathrm{Mn}](\mathrm{mg} / \mathrm{kg})=[\mathrm{Mn}](\mathrm{mg} / \mathrm{L}) *$ Final volume $(\mathrm{mL}) /$ Sample weight $(\mathrm{g})$

\section{Conclusions}

Perkin-Elmer 5100PC Atomic Absorption Spectrophotometer was used with a short part burner and nitrous oxide/acetylene flame optimized with hollow cathode lamp and a single element was measured. The background correction was selectable on an element by element basis. Water had been run between each reading; AA measurements were thus performed [7] [8].

The results of a single method for the detection of manganese in the tricalcium phosphate were obtained and are shown in Figure 1 and Tables 2-4.

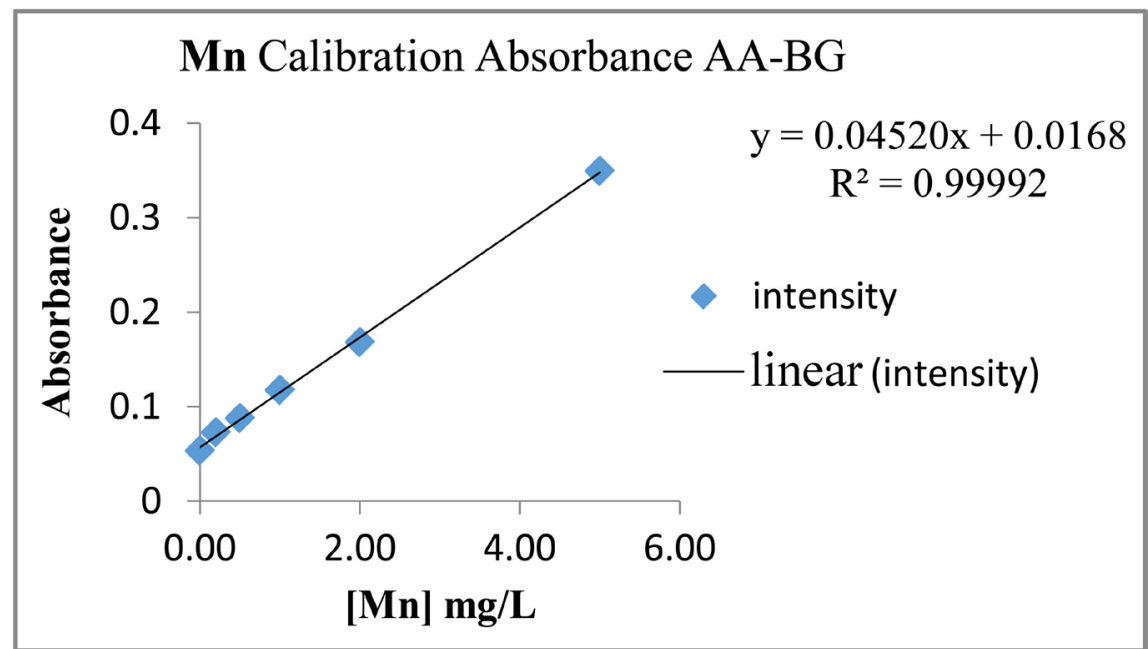

Figure 1. Calibration curve of manganese linear plot of $[\mathrm{Mn}]$ concentration against blank-corrected absorbance at $403.1 \mathrm{~nm}$. 
Table 3. Mn calibration curve data.

\begin{tabular}{cccc}
\hline$[\mathrm{Mn}](\mathrm{mg} / \mathrm{L})$ & Abs & $\mathrm{m}$ & 0.04520 \\
\hline 0.00 & 0.0002 & $\mathbf{b}$ & 0.00168 \\
0.20 & 0.0092 & $\mathbf{R}^{2}$ & 0.99992 \\
0.50 & 0.0244 & & \\
1.00 & 0.0481 & & \\
5.00 & 0.2274 & & \\
\hline
\end{tabular}

Table 4. Absorbance of sample and QA/QC study.

\begin{tabular}{|c|c|c|c|c|c|c|c|}
\hline Sample & $\mathrm{DF}$ & Absorbance & Blank-corr Ab & $\begin{array}{l}{[\mathrm{Mn}]} \\
\mathrm{mg} / \mathrm{L}\end{array}$ & $\mathrm{W}(\mathrm{g})$ & $\mathrm{V}(\mathrm{mL})$ & $\begin{array}{l}{[\mathrm{Mn}]} \\
\mathrm{mg} / \mathrm{L}\end{array}$ \\
\hline Water & & 0.0006 & & & & & \\
\hline Blank & 1 & 0.0010 & 0.0004 & & & & \\
\hline Water & & 0.0015 & & & & & \\
\hline $0.2 \mathrm{mg} / \mathrm{L}$ & 1 & 0.0107 & 0.0092 & & & & 0.18 \\
\hline Water & & 0.0019 & & & & & \\
\hline $0.5 \mathrm{mg} / \mathrm{L}$ & 1 & 0.0263 & 0.0244 & & & & 0.51 \\
\hline Water & & 0.0024 & & & & & \\
\hline $1.0 \mathrm{mg} / \mathrm{L}$ & 1 & 0.0505 & 0.0481 & & & & 1.03 \\
\hline Water & & 0.0032 & & & & & \\
\hline $2.0 \mathrm{mg} / \mathrm{L}$ & 1 & 0.0967 & 0.0935 & & & & 2.03 \\
\hline Water & & 0.0040 & & & & & \\
\hline $5.0 \mathrm{mg} / \mathrm{L}$ & 1 & 0.2314 & 0.2274 & & & & 5.00 \\
\hline Water & & 0.0046 & & & & & \\
\hline Water & & 0.0046 & & & & & \\
\hline Sample & 1 & 0.0257 & 0.0211 & 0.4297 & 1.0002 & 10 & 4.30 \\
\hline Water & & 0.0046 & & & & & \\
\hline Water & & 0.0046 & & & & & \\
\hline Sample-duplicate & 1 & 0.0258 & 0.0211 & 0.4320 & 1.0002 & 10 & 4.32 \\
\hline Water & & 0.0047 & & & & & \\
\hline Spike & 1 & 0.0484 & 0.0437 & 0.9298 & 1.0002 & 10 & 9.30 \\
\hline Water & & 0.0047 & & & & & \\
\hline Spike-duplicate & 1 & 0.0484 & 0.0437 & 0.09298 & 1.0002 & 10 & 9.30 \\
\hline Water & & 0.0050 & & & & & \\
\hline
\end{tabular}

Atomic Absorption Spectrophotometric determination of manganese in tricalcium phosphate (TCP) was found to be adequately sensitive in terms of linearity, repeatability, and accuracy. The determination of correlation coefficient $\left(R^{2}\right)$ was found to be 0.99992 . Concentration of spiking solution: $100 \mathrm{mg} / \mathrm{L}$, 
spiking solution: $0.5 \mathrm{~mL}$, sample volume: $10 \mathrm{~mL}$, spiked amount: $5.0 \mathrm{mg} / \mathrm{L}$. Average percent matrix spike recovery $(\% \mathrm{R})$ was $99.8 \%$, and relative percentage difference (\%RPD) was $0.00 \%$. The percent recovery was found to be $99.8 \%$ for spiked sample, and $99.8 \%$ for the duplicate spiked sample. The results were within the specification of $10 \mathrm{mg} / \mathrm{Kg}$ maximum, with the average concentration of $\mathrm{Mn}$ in sample found to be $4.31 \mathrm{mg} / \mathrm{Kg}$. The results meet the requirement.

\section{Acknowledgements}

The authors are thankful to Prof. Dr. Krassi Lazarova, Head of the Science Department of the Centenary University for giving us the opportunity to complete this research work.

\section{Conflicts of Interest}

The authors declare no conflicts of interest regarding the publication of this paper.

\section{References}

[1] Snell, F.D. and Snell, C.T. (1948) Colorimetric Methods of Analysis. Volume II, Third Edition, D. Van Nostrand Company, Inc., New Jersey.

[2] Toxicological Profile for Manganese July 1992, Agency for Toxic Substances and Disease Registry, United States Public Health Service.

[3] Yildiz, Y. and Dasgupta, M. (2016) Aluminum Determination for Tri-Calcium Phosphate (TCP) Anhydrous Powder by Flame Atomic Absorption Spectrophotometer. Science Journal of Analytical Chemistry, 4, 22-25. https://doi.org/10.11648/j.sjac.20160403.11

[4] USP Pharmacopeia/National Formulary (USP/NF) 38. Official Monographs, TCP.

[5] Russel, B.J., Shelton, J.P. and Wals, A. (1957) An Atomic-Absorption Spectrophotometer and Its Application to the Analysis of Solutions. Spectrochimica Acta, 8, 317. https://doi.org/10.1016/0371-1951(57)80193-3

[6] Koirtyohann, S.R. and Pickett, E.E. (1966) Spectral Interferences in Atomic Absorption Spectrometry. Analytical Chemistry, 38, 585-587. https://doi.org/10.1021/ac60236a015

[7] Flame Atomic Absorption Spectrometry Analytical Methods. Agilent Technologies, May 2017.

[8] Yildiz, Y., Jan, A. and Chien, H.-C. (2018) Determination of Tin in Trityl Candesartan by Flame Atomic Absorption Spectrophotometry (AAS). International Journal of Chemical Studies, 6, 2687-2691. 